\title{
DESENVOLVIMENTO DE ROBÔ DE SUMÔ MICROCONTROLADO POR MSP430
}

\author{
Magno Melo' \\ Italo Godoy ${ }^{2}$ \\ Marcelo Banhara ${ }^{3}$ \\ José Alvarenga ${ }^{4}$ \\ Júlio Vieira ${ }^{5}$ \\ Helosman Figueiredo ${ }^{6}$
}

Resumo: Este artigo apresenta a pesquisa e definição dos componentes necessários ao desenvolvimento de um robô autônomo a ser utilizado em competição de sumô de robôs. Este tipo de equipamento, também conhecido como robô segue faixa, será desenvolvido com o objetivo de introdução à robótica, bem como do estudo do funcionamento e aplicabilidade do microcontrolador MSP430, o qual será o componente responsável pela automação deste robô. Assim, a partir desta definição, faz-se necessária a especificação dos demais componentes integrantes do equipamento (chassi, meio de locomoção, motores, sensores e alimentação) de tal forma que o robô possa desempenhar adequadamente as tarefas para os quais o mesmo foi idealizado.

Palavras-chave: Robô; Sumô; Especificação; MSP430; Automação.

\footnotetext{
${ }^{1}$ Engenharia Elétrica/Eletrônica/UNIVAP/FEAU, Brasil, E-mail: magnomelo2004@yahoo.com.br.

2 Engenharia Elétrica/Eletrônica/UNIVAP/FEAU, Brasil, E-mail: italosonico@gmail.com.

3 Engenharia Elétrica/Eletrônica/UNIVAP/FEAU, Brasil, E-mail: marcelofb103@yahoo.com.br.

${ }^{4}$ Engenharia Elétrica/Eletrônica/UNIVAP/FEAU, Brasil, E-mail: zeh145@gmail.com.

5 Engenharia Elétrica/Eletrônica/UNIVAP/FEAU, Brasil, E-mail: juliocvieira13@gmail.com.

${ }^{6}$ Engenharia Elétrica/Eletrônica/UNIVAP/FEAU, Brasil, E-mail: helosman@gmail.com.
} 